\title{
Subcellular localisation of Cdc25A determines cell fate
}

\author{
C Leisser ${ }^{1}$, G Rosenberger ${ }^{1}$, S Maier ${ }^{1}$, G Fuhrmann ${ }^{1}$, M Grusch ${ }^{1}$, \\ S Strasser ${ }^{1}$, S Huettenbrenner ${ }^{1}$, S Fassl ${ }^{1}$, D Polgar ${ }^{1}$, S Krieger ${ }^{1}$, \\ C Cerni $^{2}$, R Hofer-Warbinek ${ }^{3}$, R deMartin ${ }^{3}$ and G Krupitza ${ }^{*, 1}$ \\ 1 Institute of Clinical Pathology, University of Vienna, Waehringer Guertel 18-20, \\ Vienna A-1090, Austria \\ 2 Institute of Cancer Research, University of Vienna, Borschkegasse 8a, Vienna \\ A-1090, Austria \\ 3 Department of Vascular Biology and Thrombosis Research, Vienna \\ International Research Co-operation Center (VIRCC), University of Vienna, \\ Brunnerstraße 59, Vienna A-1235, Austria \\ * Corresponding author: G Krupitza, Institute of Clinical Pathology, University of \\ Vienna, Waehringer Guertel 18-20, A-1090 Vienna, Austria. \\ Tel.: + 43-1-40 400/3487; Fax: + 43-1-405 34 02; \\ E-mail: g.krupitza@akh-wien.ac.at
}

Received 22.1.03; revised 01.7.03; accepted 25.7.03; published online 5.9.03 Edited by M. Blagosklonny

\begin{abstract}
Cell division cycle 25A (Cdc25A) was shown to colocalise both with nuclear and cytoplasmic proteins. Recently, we have demonstrated that overexpressed Cdc25A promoted the survival of rat 423 cells through indirect activation of PKBprotein kinase $B$. Using a Cdc25A:ER fusion protein, which can be shuttled from the cytoplasm into the nucleus, the present investigation evidences that the antiapoptotic effect of Cdc25A was restricted to its cytoplasmic localisation in rat 423 cells. In contrast, nuclear Cdc25A overexpression caused dephosphorylation and nuclear retention of the proapoptotic transcription factor Forkhead in rhabdomyosarcoma-like 1 (FKHRL1) in human N.1 ovarian carcinoma cells. This resulted in the increased constitutive expression of the FKHRL1 targets Fas ligand and Bim, and promoted apoptosis. Thus, the Cdc25A oncogene, which was found to be frequently overexpressed in certain human cancers, can increase or decrease the susceptibility to apoptosis depending on the cell-type-specific subcellular distribution.

Cell Death and Differentiation (2004) 11, 80-89. doi:10.1038/ sj.cdd. 4401318

Published online 5 September 2003
\end{abstract}

Keywords: Cdc25A; apoptosis; subcellular distribution; FKHRL1

Abbreviations: Akt, PKB-protein kinase B; ASK, apoptosis signal-regulating kinase; ATP, adenosine triphosphate; Bim, proapoptotic member of the $\mathrm{Bcl}-2$ family of proteins; Cdc25A, cell division cycle 25A; Cdk2, cyclin-dependent kinase 2; DAPI, 4'-6-diamino-2-phenylindol; DTT, DL-dithiothreitol; EDTA, ethylenediaminetetraacetic acid; ER, oestrogen receptor; FasL, Fas ligand; FCS, foetal calf serum; FITC, fluorescein isothiocyanate; GST, glutathione-S-transferase; FKHRL1, Forkhead in rhabdomyosarcoma-like 1; HEPES, ( $N$-[2-hydroxyethyl]piperazine$N$-[2-ethanesulphonic acid]); HO, Hoechst 33258; 4-OHT, 4-hydroxytamoxifen; IPTG, (isopropyl[beta]-D-thiogalactoside); NLS, nuclear localisation signal; PBS, phosphate-buffered saline; $\mathrm{PI}$, propidium iodide; PMSF, phenylmethylsulphonyl fluoride; PTEN, phosphatase dephosphorylating phosphatidylinositol 3,4,5-trisphosphate (PIP3); SDS, sodium dodecyl sulphate; TNFa, tumour necrosis factor alpha

\section{Introduction}

In a variety of malignant disorders, cell division cycle 25A (Cdc25A) is frequently overexpressed, ${ }^{1-4}$ and it has not been determined so far whether the pattern of overexpressed Cdc25A is confined to specific subcellular compartments in the distinct tumour entities. The family of Cdc25 dualspecificity phosphatases controls the cell cycle at different phases. ${ }^{5-7} \mathrm{Cdc} 25 \mathrm{~A}$ was shown to regulate $\mathrm{G} 1-\mathrm{S}$ transition by dephosphorylating threonine 14 and tyrosine 15 of cyclindependent kinase 2 (Cdk2), ${ }^{8-13}$ and by competition with p21 for cyclinA/Cdk2 and cylinE/Cdk2 binding sites. ${ }^{14}$ Moreover, Cdc25A degradation is part of a DNA-damage checkpoint mechanism. ${ }^{15}$ This implicates that Cdc25A activity is focused to the cell nucleus. However, Cdc25A also interacts with Raf1 by virtue of 14.3.3 proteins $^{16-18}$ and apoptosis signalregulating kinase (ASK)1. ${ }^{19}$ This, in contrast, points to a cytoplasmic function of Cdc25A. It was demonstrated recently that in rat 423 cells the bulk of Cdc25A was actually localised in the cytoplasm and that apoptosis was inhibited by Cdc25A due to the PKB-protein kinase B (Akt) survival pathway activation. ${ }^{18}$ In contrast, endogenous and ectopic Cdc25A is found in the nucleus in N.1 human ovarian carcinoma cells. The question arose as to how far the spatial distribution of Cdc25A is relevant for its antiapoptotic function.

\section{Results}

\section{Distinct expression of Cdc25A in rat 423 cells and N.1 ovarian carcinoma cells}

In earlier studies, it was shown that overexpressed Cdc25A promoted apoptosis in $\mathrm{N} .1$ cells, ${ }^{20}$ which in contrast was prevented in rat 423 cells. ${ }^{18}$ Immunocytochemistry (Figure 1a) and Western blot analysis of fractionated cell lysates (Figure $1 b$ ) revealed that endogenous as well as ectopic Cdc25A was predominantly expressed in the cytoplasm in rat 423 cells, whereas it was restricted to the nuclei in N.1 cells. The analysis of two additional ovarian carcinoma cell lines (HTB-77, M-134) and two breast cancer cell lines (SKBr3 and T47D) revealed that these cell lines also expressed Cdc25A in the nucleus (Figure 1c). Therefore, rat 423 cells were used for further studies regarding the cytoplasmic expression and function of Cdc25A.

\section{Cdc25A causes dephosphorylation and activation of FKHRL1}

In a search for nuclear proteins that elevate the susceptibility to apoptosis when dephosphorylated (e.g. by Cdc25A), we 
a

rat 423

Co
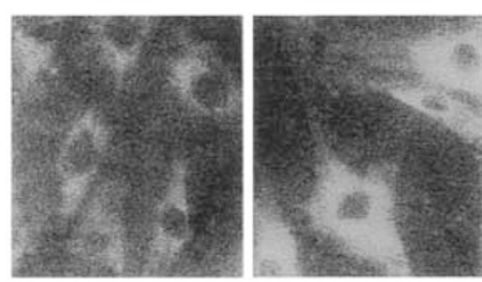

b

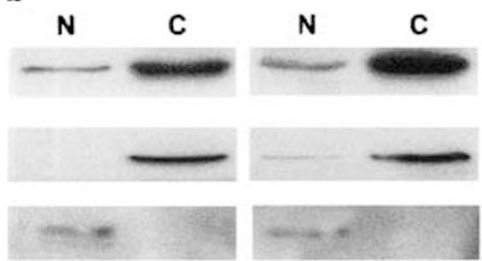

C

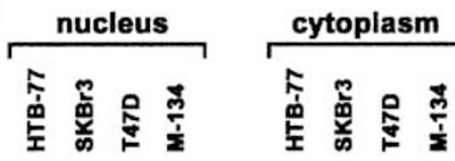

N.1
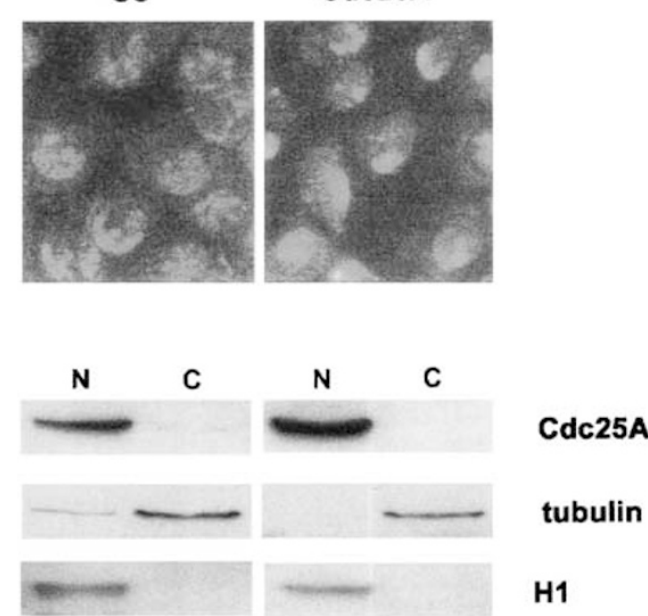

Cdc25A

tubulin

H1

Figure 1 Detection of subcellular localisation of endogenous and ectopic Cdc25A in rat 423 and human N.1 ovarian carcinoma cells. (a) To detect Cdc25A overexpression by indirect immunofluorescence, the cell clones were grown on siliconised glass slides, then the cells were fixed and incubated with anti-Cdc25A antibody (SC-97), as described in 'Materials and Methods'. Only the nuclei of N.1 cells are stained, but they are larger than the nuclei of rat 423 cells. The intensively stained agglomerations in the Cdc25A-overexpressing N.1 cells are also strictly nuclear. For control, slides were exposed to the second antibody only (not shown). (b) Nuclear (N) and cytoplasmic (C) fractions were prepared from N.1 and rat 423 clones and analysed by Western blotting as described in 'Materials and Methods'. Rat 423 and N.1 cells were either transfected with Cdc25A cDNA (Cdc25A) or with an empty vector (Co). The purity of the subcellular fractions was controlled by analysing the expression of tubulin and histon H1. (c) Detection of subcellular localisation of Cdc25A in human ovarian and breast carcinoma cell lines. Nuclear and cytoplasmic extracts of HTB-77 and M-134 cells (ovarian carcinoma) and of T47D and SKBr3 cells (breast carcinoma) were analysed by Western blotting with monoclonal antiCdc25A antibody (Abcam, ab2357). The purity of the subcellular fractions was controlled by analysing the expression of tubulin and histon $\mathrm{H} 1$

analysed the expression and the phosphorylation status of the Forkhead transcription factor family members FKHR, Forkhead in rhabdomyosarcoma-like 1 (FKHRL1) and AFX (FOXO4) in Cdc25A-overexpressing N.1 cells, and in N.1control cells. Tumour necrosis factor alpha (TNFa) induced the apoptosis of N.1 cells only under serum-deprived culture conditions. Therefore, all the analyses were performed with serum-starved cells. FKHR could not be detected in N.1 clones and AFX did not exhibit a distinct phosphorylation pattern in the cell clones analysed (data not shown). In N.1 cells, FKHRL1 accumulated in the nucleus under serumstarved conditions, which was also shown by others in different cell systems, ${ }^{21,22}$ and nuclear expression of FKHRL1 was further increased in Cdc25A-overexpressing cells (Figure 2a, upper panel, compare lanes 1 and 5). It was demonstrated that 14.3 .3 proteins bind to phosphorylated FKHRL1 ( $p F K H R L 1$ ) and cause its relocation from the nucleus into the cytoplasm ${ }^{23,24}$ where it becomes rapidly degraded. Nevertheless, pFKHRL1 was still detected as double bands by anti-pFKHRL1 antibody in the nuclei of N.1control cells and N.1-Cdc25A cells under serum-deprived conditions. However, in N.1-Cdc25A cells, the phosphorylation level of FKHRL1 was 2.5-fold reduced compared to N.1control cells. This was calculated on the basis of densitometry measurements of pFKHRL1 bands (lane 1 versus lane 5, second panel), which were set in relation to total FKHRL1 protein expression levels (lane 1 versus lane 5, upper panel), and further standardised by histon $\mathrm{H} 1$ expression levels (fourth panel).

Taken together, this implicated that Cdc25A mediated the dephosphorylation of FKHRL1 and caused its nuclear retention.

The slower migrating band of the pFKHRL1 double bands was not detected by the anti-pFKHRL1 antibody in Cdc25Aoverexpressing N.1 cells after treatment with TNFa (indicated by an arrow, Figure 2a, second panel, compare lanes 3 and 7 ). 


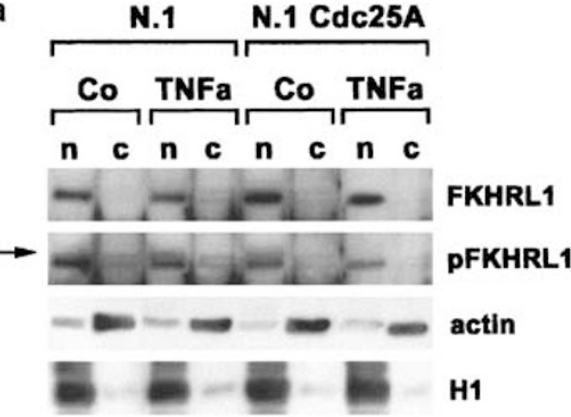

b

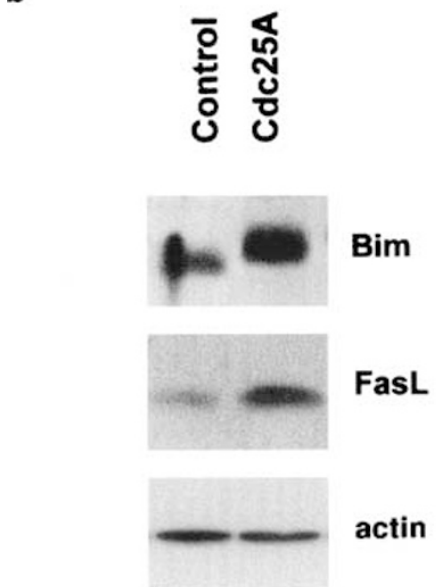

C

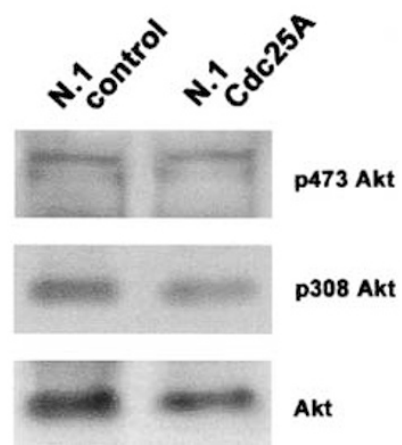

Figure 2 (a) Expression and phosphorylation of FKHRL1 in distinct N.1 clones following TNFa treatment. Control cells (N.1) and Cdc25A-overexpressing cells (N.1-Cdc25A) were grown to $50 \%$ confluence, then the serum was withdrawn for $24 \mathrm{~h}$ and cells were treated for another $8 \mathrm{~h}$ with TNFa $(40 \mathrm{ng} / \mathrm{ml})$. Nuclear $(\mathrm{N})$ and cytosolic $(C)$ fractions were prepared and analysed by Western blotting using anti-FKHRL1 (upper panel) and anti-phosphoT 32 FKHRL1 (pFKHRL1; second panel) antibodies. The arrow indicates a higher phosphorylated form of FKHRL1, which migrates slower. The purity of the subcellular fractions and equal sample loading was controlled by analysing the expression of beta-actin and histon $\mathrm{H} 1$ (third and fourth panels). (b) Expression of Bim, FasL and beta-actin in N.1-pwzl clones. Total protein of N.1-Cdc25A (Cdc25A) and N.1-control cells was isolated and separated on SDS-PAGE, transferred onto PVDF membranes and immunoblotted with anti-Bim, anti-FasL and anti-beta-actin antibodies. (c) Phosphorylation of Akt in N.1 clones. Total protein of N.1-Cdc25A (Cdc25A) and N.1-control cells was isolated and separated on SDS-polyacrylamide gels, transferred onto PVDF membranes and immunoblotted with an antibody directed against phospho-serine 473 of Akt (p473Akt) and phospho-theronine 308 of Akt (p308Akt). For control reasons, the total Akt expression (Akt) was also investigated
This substantiated the former observation that nuclear overexpression of the phosphatase Cdc25A promoted the dephosphorylation of FKHRL1.

Only the nuclear localisation of the FKHRL1 transcription factor enables the transactivation of its target genes such as $\mathrm{Bim}$ and fasL $\mathrm{L}^{23,25,26}$ Western blot analyses of $\mathrm{Bim},{ }^{26,27}$ and FasL $^{23,28}$ evidenced increased expression in N.1-Cdc25A cells compared to N.1 controls, whereas the expression of actin, which is not controlled by FKHRL1, remained unchanged (Figure 2b).

It was shown that cytoplasmic Cdc25A indirectly activated Akt by inducing phosphorylation of Akt-threonine 473 presumably by involvement of Raf $1 .{ }^{18}$ Akt is a kinase regulating FKHRL1 phosphorylation, and Akt activity itself is regulated by phosphorylation. Therefore, the phosphorylation levels of Akt at serine 473 and at threonine 308 were investigated. Figure $2 \mathrm{c}$ demonstrates that neither of the two sites of Akt became differently phosphorylated in Cdc25A-overexpressing or N.1-control cells, which made an Akt-mediated alteration of FKHRL1 phosphorylation in Cdc25A-overexpressing cells unlikely.

Next, we investigated whether Cdc25A interacted directly with FKHRL1. A glutathione-S-transferase fusion construct (GST-FKHRL1), which was expressed in Escherichia coli, was bound to glutathione-sepharose and incubated with native N.1 cell lysate (containing a phosphatase inhibitor) and adenosine triphosphate (ATP) to phosphorylate GSTFKHRL1. However, the specific binding of Cdc25A (which was contained in native N.1 cell lysates as an endogenous protein) to FKHRL1 could not be detected. The faint Cdc25A bands showing up in the presence of GST-FKHRL1 and GST alone (control) were nonspecific contaminations, which remained trapped by sepharose (Figure 3 ). Even the addition of $150-800 \mathrm{ng}$ of recombinant active Cdc25A to phosphory-

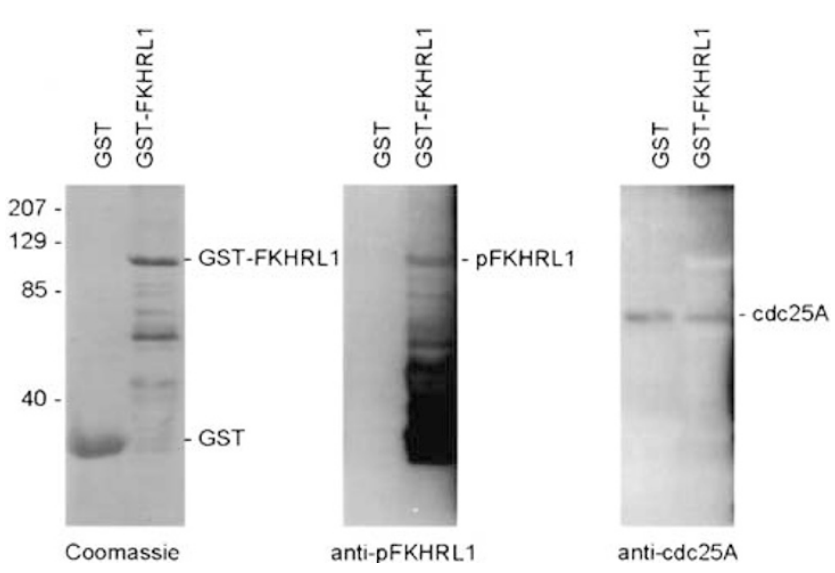

Figure 3 Interaction of Cdc25A with FKHRL1. GST-FKHRL1 and GST (fo control reasons) was bound to glutathione-sepharose and incubated with native $\mathrm{N} .1$ cell protein lysate and $1 \mathrm{mM}$ ATP at room temperature for $20 \mathrm{~min}$ to phosphorylate GST-FKHRL1 (pGST-FKHRL1) and to promote the binding of Cdc25A to the potential substrate. Then, the incubation was terminated, GSTsepharose and GST-FKHRL1-sepharose were washed and centrifuged, resuspended in PAGE sample buffer, boiled and subjected to electrophoretic separation and Western blot analysis. The expression of GST and GST-FKHRL (Coomassie blue staining; left panel), the phosphorylation level of GST-FKHRL1 (middle panel) and the presence of Cdc25A (right panel) were analysed by Western blotting 
lated GST-FKHRL1 did not show a specific interaction (data not shown). Furthermore, IP-Western assays, which were performed with native N.1 cell lysates, could not demonstrate a direct interaction of Cdc25A with FKHRL1 (data not shown). Therefore, the dephosphorylation of FKHRL1 in the presence of overexpressed Cdc25A was not mediated by a direct mechanism.

\section{Cdc25A overexpression supports TNFa-induced apoptosis of $\mathrm{N} .1$ cells}

Increased FKHRL1 activity was expected to enforce an apoptotic response due to the transcription of FasL and Bim. $^{29}$ Therefore, apoptosis was measured in Cdc25A-overexpressing N.1 cells. To obtain comparable results, Cdc25A was introduced into N.1-pwzl cells by retroviral transduction (see 'Materials and Methods'). In N.1 cells, it was demonstrated that the induction of apoptosis by TNFa and benzamide riboside repressed endogenous Cdc25A. ${ }^{30,31}$ Hence, we analysed the expression of Cdc25A in the presence of TNFa by Western blotting to confirm that ectopic Cdc25A remained expressed (Figure 4a). This was essential for the performance of subsequent experiments. To determine cell death rates, N.1-Cdc25A and N.1-control cells, were exposed to TNFa for $96 \mathrm{~h}$ (Figure 4b). On average, TNFa induced $23.8 \%$ cell death in control cells and $82.7 \%$ cell death in Cdc25A-overexpressing clone pools after $96 \mathrm{~h}$ (three independently pooled clones, triplicate experiments). Thus, in analogy to Myc-induced apoptosis, ${ }^{32}$ there was also a Cdc25A-dependent increase in cell death rates. Also, in a particular subclone of Rat1 fibroblasts ${ }^{33}$ and in vascular smooth muscle cells, ${ }^{34}$ Cdc25A promoted apoptosis.

Cdc25A is known to activate Cdk2 and the improper activity of cell cycle protagonists (i.e. Cdk2) may be a potent apoptotic trigger. Therefore, the effect of Cdk2 overexpression on the induction of apoptosis was investigated. However, N.1 cells, in which cdk2 cDNA was stably introduced (Figure 5a), did not show significant differences upon TNFa-induced apoptosis when compared to controls containing an empty vector (Figure 5b). Also, rat 423 cells did not exhibit increased apoptosis rates when Cdk2 was overexpressed (data not shown).

\section{Cytoplasmic expression of Cdc25A:ER promotes survival}

To study the effect of cytoplasmic Cdc25A in a conditional model, the cDNA of Cdc25A was fused to a Tamoxifen (4hydroxytamoxifen, 4-OHT)-responsive mutant of the oestrogen receptor (ER) resulting in a Cdc25A:ER construct. In the absence of 4-OHT, Cdc25A:ER localises in the cytoplasm. Therefore, a cell line was required, in which the nuclei were constitutively Cdc25A depleted (i.e. rat 423 cells), otherwise the nuclear expression of endogenous Cdc25A and cytoplasmic expression of ectopic Cdc25A:ER would have biased the readout of the survival assays. Since N.1 cells and the cell lines HTB-77, M-134, SKBr3 and T47D expressed endogenous Cdc25A in the nucleus, we had to use rat 423 cells, in a

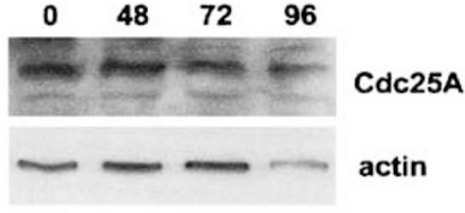

b

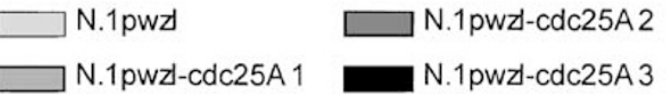

TNFa mediated cell death in N.1pwzl clones

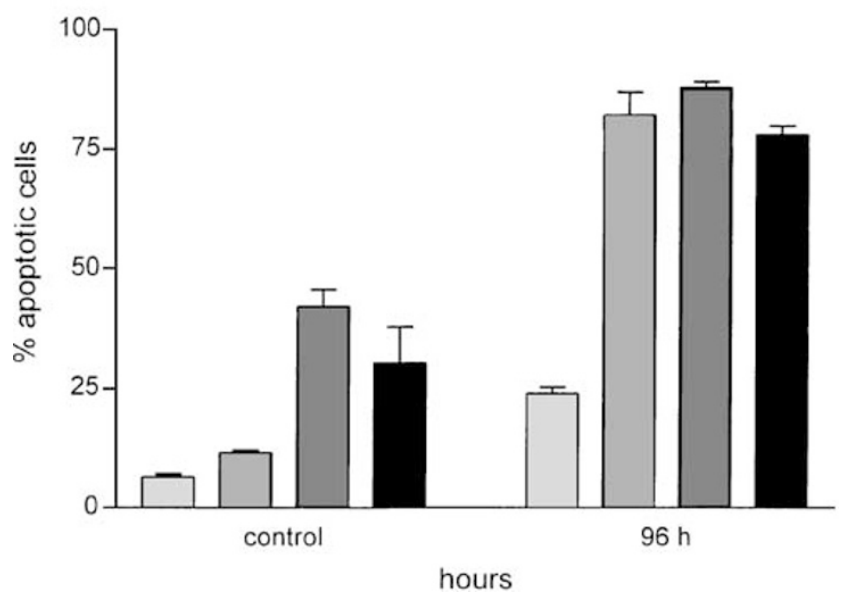

Figure 4 (a) Sustained expression of ectopic Cdc25A upon treatment with TNFa. N.1-Cdc25A cells were grown to $50 \%$ confluence, then the serum was withdrawn for $24 \mathrm{~h}$ and $40 \mathrm{ng} / \mathrm{ml}$ TNFa was added for the times (in hours) indicated. Thereafter, total protein was isolated and Cdc25A expression was investigated by Western blot analysis. To control sample loading, the expression of beta-actin was analysed. (b) Cell death rates upon TNFa-treatment of independent $\mathrm{N} .1$ clones expressing ectopic Cdc25A. Independently pooled N.1pwzl clones were grown in $10 \%$ FCS, then the serum was withdrawn for $24 \mathrm{~h}$ and thereafter clones were treated with $40 \mathrm{ng} / \mathrm{ml}$ TNFa for $96 \mathrm{~h}$. Cells floating in the supernatant were pooled with cells, which were trypsinised from the culture dish, stained with $\mathrm{HO} / \mathrm{PI}$ and apoptotic cells were identified and counted under UV light in conjunction with a DAPI filter using an inverse microscope. Values represent averages from triplicate experiments with three independent pooled clones (1, 2 and 3). Error bars indicate S.E.M. Significance (s; t-test): Control: N.1 versus Cdc25A 1, $P=0.041$ (non-s); N.1 versus Cdc25A 2, $P=0.0006$ (s); N.1 versus Cdc25A 3, $P=0.0357$ (non-s); 96 h TNFa: N.1 versus Cdc25A 1, $P=0.0003$ (s); N. 1 versus Cdc25A 2, $P=0.0001$ (s); N.1 versus $C d c 25 A 3, P=0.0001$ (s)

which the nuclei were devoid of endogenous Cdc25A, and therefore the Cdc25A:ER fusion construct was stably transfected into this cell line. The ectopic expression of Cdc25A:ER was analysed by Western blotting with anti-ER and antiCdc25A antibodies (Figure 6a). To confirm the conditional, 4OHT-mediated translocation of Cdc25A:ER from the cytoplasm into the nuclei, cells were grown in $10 \%$ foetal calf serum (FCS), treated with 4-OHT for 2, 4 and $8 \mathrm{~h}$, and then cytoplasmic and nuclear extracts were prepared and analysed by Western blotting. In response to 4-OHT, cytoplasmic Cdc25A:ER levels decreased time dependently and were redistributed into the nuclei, because the nuclear Cdc25A:ER level increased after $2 \mathrm{~h}$ of $4-\mathrm{OHT}$ treatment. Unexpectedly, after $8 \mathrm{~h}$ of $4-\mathrm{OHT}$ treatment, the nuclear expression levels of Cdc25A:ER decreased (Figure 6b). 


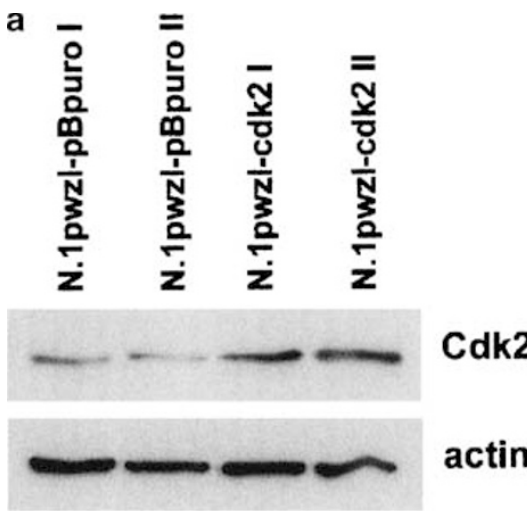

b DII N.1pwzl-pBpuro । N.1pwz-cdk2 I N.1pwz-cdk2 ॥

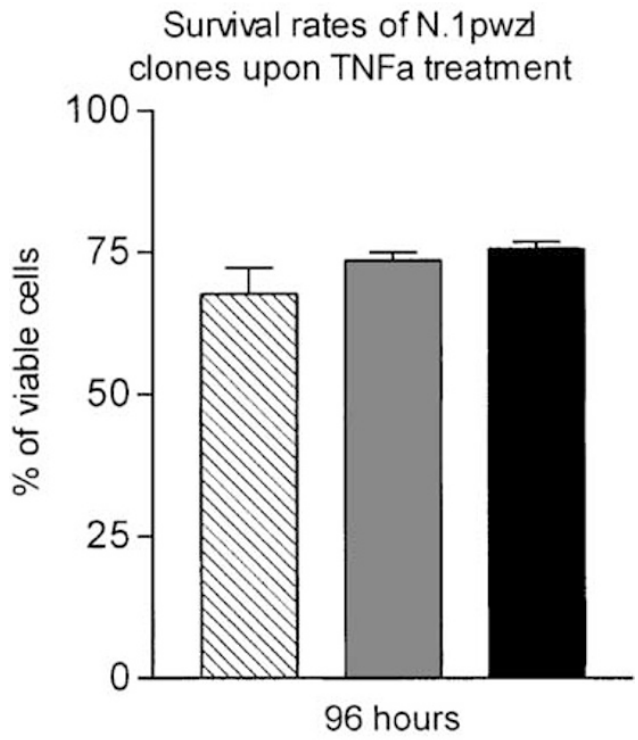

Figure 5 Effect of Cdk2 overexpression in N.1 ovarian carcinoma cells on survival. (a) Expression of Cdk2 was analysed in N.1-pwzl cells, in which cdk2 cDNA (in vector pBpuro) was stably introduced (cdk2 I and cdk2 II are two independently pooled clones). For control reasons, an empty vector was introduced (pBpuro I and pBpuro II are two independently pooled clones). (b) After withdrawal of serum for $24 \mathrm{~h}$, the independent clones were exposed to $40 \mathrm{ng} / \mathrm{ml} \mathrm{TNFa}$ for $96 \mathrm{~h}$. Then, adherent cells were trypsinised and counted. The marginal differences in the survival rates of control and Cdk2-overexpressing N.1-pwzl clones were not significant (t-test). Error bars indicate S.E.M.

After the induction of apoptosis by serum withdrawal, the survival rates of rat 423 control and Cdc25A:ER-expressing cells were determined. In previous investigations, it was shown that the ectopic overexpression of cytoplasmic Cdc25A prevented apoptosis of rat 423 cells, ${ }^{18}$ and here we demonstrate that Cdc25A:ER also accumulated in the cytoplasm in the absence of 4-OHT and rendered rat 423 cells refractory to apoptosis (Figure $6 \mathrm{c}$ ). In the presence of 4$\mathrm{OHT}$ (added $2 \mathrm{~h}$ after serum withdrawal), the antiapoptotic effect of Cdc25A:ER was reverted. Hence, Cdc25A prevented apoptosis only when it was localised in the cytoplasm. The proapoptotic effect of nuclear Cdc25A:ER (upon 4-OHTmediated relocation) was weak, because Cdc25A:ER became rapidly degraded in the nuclei of 423 cells, but it was significant (see Figure 6c).

\section{Discussion}

Former work regarding the function of Cdc25A raised indirect evidence for its ubiquitous distribution within cells. On the one hand, Cdc25A was described as a key regulator of G1-S transition by dephosphorylating $\mathrm{Cdk}^{8}$ and this implicated that Cdc25A is active in the nucleus. On the other, Cd25A also interacts with Raf 1 by virtue of 14.3 .3 proteins, ${ }^{16,17}$ implicating a cytoplasmic activity of Cdc25A.

In rat 423 cells, the bulk of anti-Cdc25A immunostaining was in fact localised in the cytoplasm. ${ }^{18}$ This was confirmed by immunoblotting rat 423 nuclear and cytoplasmic protein extracts (Figures $1 \mathrm{a}$ and b). In rat 423 cells, cytoplasmic Cdc25A was shown to activate the Akt-survival pathway indirectly, thereby preventing apoptosis. ${ }^{18}$ Another report demonstrated that Cdc25A inhibited cytoplasmic ASK1 independent of its phosphatase activity, thereby blocking cell death triggered by oxidative stress. ${ }^{19}$ Hence, we fused the cDNA of Cdc25A to that of ER, which allows for Tamoxifen (4-OHT)-mediated shuttle of the Cdc25A:ER protein from the cytoplasm into the nucleus. The results from this investigation suggested that $\mathrm{Cdc} 25 \mathrm{~A}$ protected from apoptosis only when it was localised in the cytoplasm, because upon 4-OHT treatment, the cytoplasmic Cdc25A:ER level diminished and increased in the nuclei of rat 423 cells within $2 \mathrm{~h}$, followed by degradation within $8 \mathrm{~h}$. Hence, the loss of antiapoptotic function of Cdc25A:ER correlated with the decreased cytoplasmic expression upon exposure to 4-OHT. The rapid nuclear degradation of imported Cdc25A:ER (mediated by 4-OHT) may explain why the proapoptotic effect of (short-lived) nuclear Cdc25A:ER was weak (but significant).

Upon treatment with 4-OHT, the decay of nuclear Cdc25A:ER might have been triggered by the ER portion and ubiquitination of ER might have also tagged Cdc25A to proteasomal degradation. The stability of ER was shown to depend on the type of ligand bound to ER and on the cellular context. ${ }^{35}$ Alternatively, Cdc25A itself might have been the prime target for proteolytic degradation as soon as it was relocalised to the nucleus of rat 423 cells. Since the bulk of endogenous Cdc25A was found in the cytoplasm, but not in the nuclei of rat 423 cells, this favours the possibility of nucleus-specific proteolysis of Cdc25A in this cell line and makes rat 423 cells a valuable tool to study spatial functions of Cdc25A. Furthermore, Cdc25A contains both a nuclear localisation signal and a nuclear export signal, and it is possible that either of the two mechanisms might be dysregulated, thereby causing a decrease in nuclear Cdc25A levels. Future work in our lab will focus on the subcellular expression of Cdc25A in distinct cell types and on physiological relocation mechanisms.

As pointed out in this investigation, Cdc25A accumulated a priori in the nuclei of N.1 human ovarian carcinoma 
a

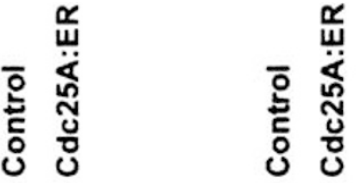

Cdc25A:ER -

ن

잉

ER -

$-95$

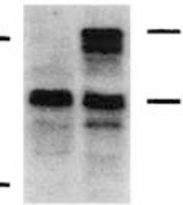

Cdc25A:ER

Cdc25A

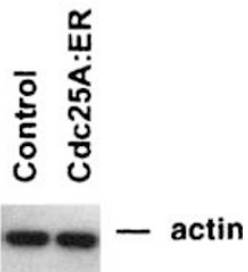

\section{$\begin{array}{lllllllll}\text { b } & 0 & 2 & 4 & 8 & 0 & 2 & 4 & 8\end{array}$}
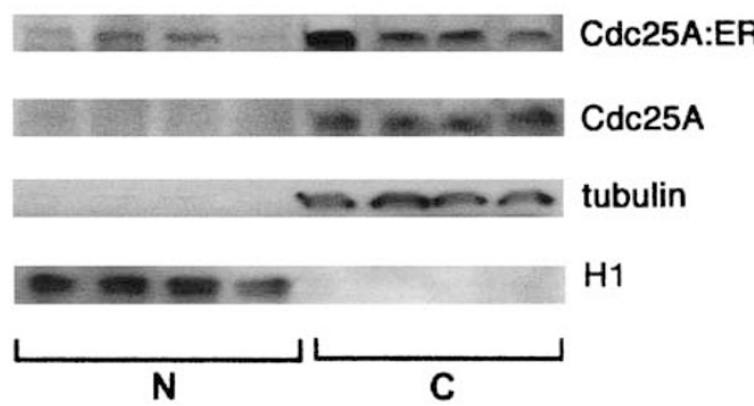

\section{tubulin}

H1

\section{c Suvival rates}

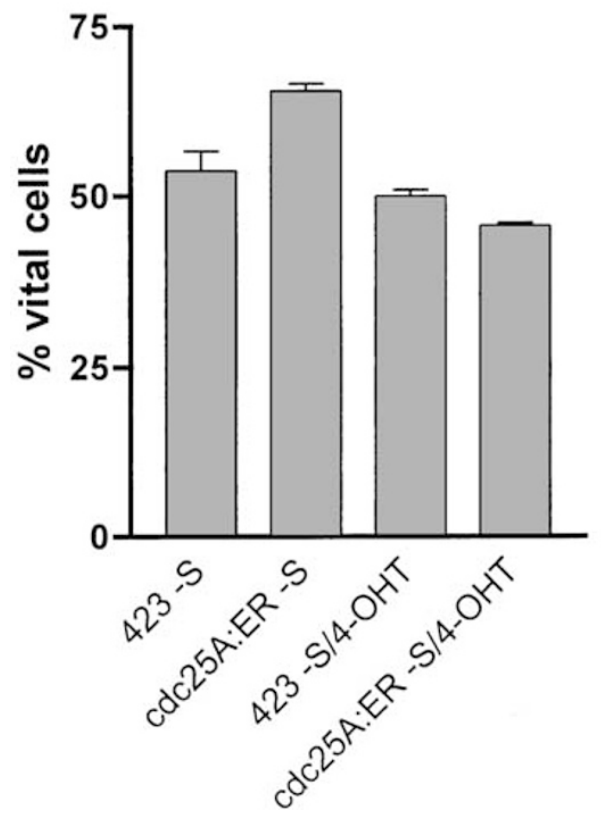

Figure 6 (a) Ectopic Cdc25A:ER expression in rat 423 cells. Total protein of rat 423-Cdc25A:ER cells (clone B/N2; Cdc25A:ER) and of rat 423 (Control) cells was isolated and separated on SDS-PAGE, transferred onto a PVDF membrane and immunoblotted with anti-ER $\alpha$ (left side panel) and anti-Cdc25A (SC-7157; right side panel) antibodies. Equal loading was confirmed by analysing beta-actin expression. (b) 4-OHT-mediated subcellular shuttle of Cdc25A:ER. Cdc25A:ER-expressing rat 423 cells were treated with 4-OHT $(750 \mathrm{nM})$ for $0,2,4$ and $8 \mathrm{~h}$. Then nuclear $(\mathrm{N})$ and cytoplasmic $(\mathrm{C})$ fractions were isolated and analysed by Western blotting with an anti-Cdc25A (SC-7389) antibody. The upper panel shows ectopic Cdc25A:ER-expression and the second panel shows endogenous Cdc25A-expression. The purity of the subcellular fractions was controlled by analysing the expression of tubulin and histon $\mathrm{H} 1$ (third and fourth panels). (c) Survival rates of Cdc25A:ER-expressing rat 423 cells upon serum deprivation and 4-OHT treatment. Cells were grown in $10 \%$ FCS to confluence, then the serum was withdrawn. After $2 \mathrm{~h}, 4-\mathrm{OHT}$ ( $500 \mathrm{nM}$ ) was added. After $24 \mathrm{~h}$, viable cells that remained attached to the culture plate were trypsinised and counted. Values show the average of triplicate experiments in percent. Error bars indicate S.E.M. Significance (s; $t$-test): 423 versus Cdc25A:ER, $P=0.0014$ (s); 423 versus $423+4-\mathrm{OHT}, P=0.2308$ (non-s); 423 versus Cdc25A:ER $+4-0 H T$, $P=0.0005$ (s); $423+4-\mathrm{OHT}$ versus Cdc25A:ER $+4-\mathrm{OHT}, P=0.0001$ (s) 
cells. Therefore, a survival-promoting effect of Cdc25A seemed unlikely. Notably, ectopic Cdc25A overexpression resulted in increased spontaneous apoptosis rates in pooled N. 1 clones.

The ectopic overexpression of Cdc25A was $\sim 2$-fold in N.1 cells and that of Cdc25A:ER 3-fold in rat 423 cells. Also in earlier investigations, ${ }^{18}$ we did not observe that ectopic Cdc25A was expressed beyond two- to three-fold over endogenous expression. We assume that excessive (nuclear) expression has adverse effects for these cells, and therefore such clones, which vastly overexpress Cdc25A, will vanish by negative selection. Surprisingly, even in rat 423 cells, in which Cdc25A was shown to predominate in the cytoplasm and protects from apoptosis, only a two- to three-fold overexpression was observed in a panel of 12 independent Cdc25A overexpressing clones. This suggests that in various cell types, only a limited level of Cdc25A expression is tolerated and further implicates that Cdc25A seems to be a fine-tuned key regulator (perhaps even rate limiting) for different cellular processes. This assumption is supported by the fact that even moderate overexpression of Cdc25A caused dramatic effects that are beyond a direct correlation with respect to the expression level. Interestingly, the constitutive Cdc25Aexpression levels of HTB-77 versus $\mathrm{M}-134$ ovarian carcinoma cells differed by a factor of $\sim 10$. It can be speculated that HTB-77 possess an appropriate (distorted) genetic background, which allows for this high Cdc25A expression without adverse effects.

This investigation furthermore demonstrates that at least phospho-threonine 32 of FKHRL1, which targets FKHRL1 for 14.3.3-mediated cytoplasmic export, became dephosphorylated upon nuclear Cdc25A overexpression in N.1 cells. FKHRL1 is a transcription factor ${ }^{23,28,36,37}$ and to be active its nuclear abundance is mandatory. Also phosphorylation at serine 253 defines cytoplasmic localisation by disrupting a nuclear localisation signal (NLS) on FKHRL1. ${ }^{36}$ Both phosphorylation sites may cooperate in determining the subcellular distribution of FKHRL1. The regulatory functions of phosphorylated serine 315 and of other phosphosites are currently unknown. Dephosphorylation of FKHRL1 is necessary for its nuclear retention and in fact the level of nuclear FKHRL1 was elevated in Cdc25A-overexpressing N.1 cells. This may have caused the activation of $\mathrm{FasL}^{28,23}$ and Bim transcription, 27,26 and the enhanced apoptotic response in Cdc25A-overexpressing N.1 cells.

The dephosphorylation of FKHRL1 requires a direct interaction with phosphatase(s). However, neither in vitro binding studies with a GST-FKHRL1 fusion protein nor pulldown assays from native cell extracts (data not shown) confirmed direct binding of Cdc25A to FKHRL1. Hence, Cdc25A seems unlikely to dephosphorylate FKHRL1 itself, but to either induce another phosphatase or to inactivate a kinase that regulates FKHRL1 phosphorylation. It was reported that FKHRL1 becomes directly phosphorylated by kinases such as Akt, ${ }^{23,28,38,39}$ whereas PTEN mediates indirect dephosphorylation of FKHRL1. ${ }^{40}$

In conclusion, this study demonstrates that the nuclear overexpression of Cdc25A indirectly mediated the dephosphorylation of threonine 32 of FKHRL1 and promoted apoptosis, whereas the cytoplasmic overexpression of Cdc25A was apoptosis protective.

Since numerous human cancers overexpress Cdc25A, ${ }^{1-4}$ the determination of the spatial expression may be relevant to evaluate its impact on prognosis and therapy.

\section{Materials and Methods}

\section{Materials}

Human cdc25A cDNA was a kind gift from Dr. David Beach (Cold Spring Harbour Laboratories, NY, USA), cdk2 cDNA was a gift from Dr. Hannes Hofmann (IMP, Vienna), the pBabe-puro (pBpuro) vector was a gift from Dr. Trevor Littlewood (ICRF, London, UK), the GST-FKHRL1 fusion construct was a gift from Dr. Anne Brunet (Harvard, Boston, USA) and the pwzl plasmid was a gift from Dr. Manuel Serrano (National Center of Biotechnology, Madrid, Spain). The Phoenix ecotropic packaging cell line was a gift from Dr. Gary Nolan, (Department of Molecular Pharmacology, Stanford University School of Medicine). The cell lines HTB-77 and M-134 were a gift from Dr. Thomas Grunt and T47D cells were a gift from Dr. Sabine Wohlfart (both University of Vienna, Vienna).

The recombinant active CDC25A enzyme $(10 \mathrm{U} / \mu \mathrm{l} ; 61 \mathrm{U} / \mu \mathrm{g})$ was obtained from Upstate. Anti-Cdc25A (Abcam ab2357) 1:250, antiCdc25A (Santa Cruz, sc-97) 1:10000, anti-Cdc25A (sc-7157) 1:5000, anti-Cdc25A (sc-7389) 1:200, anti-Cdk2 (sc-163) 1:10000, anti-histon $\mathrm{H} 1$ (sc-8030) 1:20000, anti-tubulin (sc-8035) 1:20000, anti-ER $\alpha$ (sc542) 1:500, anti-Akt (Cell Signaling \#9272) 1:1000, anti-P-Akt (Thr 308; Cell Signaling \#9275) 1:1000, anti-phospho (Thr32) FKHRL1 (Cell Signaling \#9464) 1:1000, anti-phospho-AFX (Cell Signaling \#9471) 1:1000, anti-FKHRL1 (Upstate \#06-951) 1:500, anti-FasL (BD Transduction Lab. 610410) 1:1000, anti-Bim (Pro Sci. Inc. 2065) 1: 1000 and anti-beta-actin (Sigma, A5441) $1: 20000$ were used for Western blotting in the indicated dilutions.

\section{Cell culture}

Ovarian carcinoma cell lines HTB-77 and M-134 were grown in alphaMEM, the breast cancer cell line SKBr3 was grown in McCoys medium and the breast cancer cell line T47D and rat 423 cells were grown in DMEM, all containing 10\% FCS and 1\% penicillin-streptomycin. Rat 423-Cdc25A:ER cells were grown in DMEM containing 10\% FCS, $1 \%$ penicillin-streptomycin and $2 \mu \mathrm{g} / \mathrm{ml}$ puromycin.

The monoclonal human ovarian adenocarcinoma N.1 cell line is a derivative of the heterogeneous HOC-7 cell line that was cultured in MEM supplemented with 10\% FCS (GIBCO, Paisley, UK), penicillin-streptomycin $\left(100 \mathrm{U} / \mathrm{ml}-100 \mu \mathrm{g} / \mathrm{ml}\right.$, Gibco-BRL) (medium A), at $37^{\circ} \mathrm{C}$ in a humidified atmosphere containing $5 \% \mathrm{CO}_{2}$.

N.1-pwzl cells were grown in MEM containing $200 \mu \mathrm{g} / \mathrm{ml} \mathrm{G-418}$ sulphate.

N.1-pwzl-Cdc25A and N.1-pwzl-Cdk2 cells (both in pBpuro), and N.1pwzl-pBpuro cells (control) were grown in a-MEM with the addition of $0.4 \mu \mathrm{g} / \mathrm{ml}$ puromycin and $200 \mu \mathrm{g} / \mathrm{ml} \mathrm{G-418} \mathrm{sulphate.}$

\section{Subcloning procedures}

The cdc25a or egfp (for control reasons) cDNA was subcloned into the Xhol and Notl site of the $\mathrm{pCl}^{\text {neo }}$ mammalian expression vector, which contains a CMV promotor (Promega, Mannheim, Germany) or blunt end ligated into the SnaBI site of pBpuro. 
Cdc25A:ER construction: The cdc25a cDNA was released from the pBluescript vector with BssHII and BsiGl. In all, $5^{\prime}$ overhangs were filled with Klenow and ligated into the Klenow-filled BamHI site of Myc:ER that is inserted in the pBpuro vector (BamHI releases myc from this construct, which was a kind gift of Trevor Littlewood ${ }^{41}$ ). The correct reading frame was checked by DNA sequencing. C-terminal loss of six amino acids does not infringe the active centre of the Cdc25A phosphatase domain

\section{Transfection of cells}

Rat 423 cells were plated into $60 \mathrm{~mm}$ dishes and grown for 2 days to 40-50\% confluence. Lipofection of cells with Cdc25A:ER cDNA (in $\mathrm{pBpuro}$ ) was performed utilising the Transfectam reagent (Promega). The cells were washed once with prewarmed DMEM without FCS. A total of $5 \mu \mathrm{g}$ DNA $(1 \mu \mathrm{g} / \mu \mathrm{l})$ and $10 \mu \mathrm{l}$ Transfectam were separately pipetted into $0.75 \mathrm{ml}$ DMEM each and then both mixtures were combined. Transfectam-DNA complexes were allowed to form for $10 \mathrm{~min}$ and were then applied onto rat 423 cells for $3 \mathrm{~h}$ in a humidified incubator. The transfection was stopped by adding $4 \mathrm{mI}$ DMEM containing $10 \% \mathrm{FCS}$. The next day, the cells were split into new dishes with a fresh medium and $48 \mathrm{~h}$ after transfection, selection drug $2 \mu \mathrm{g} / \mathrm{ml}$ was added and single clones were isolated with cloning cylinders and were propagated separately. Where indicated, pooled clones were propagated.

\section{Generation of ecotropic mouse retrovirus transducible N.1 human ovarian carcinoma cells}

N.1 cells were stably pretransfected with mouse retrovirus receptor (pwzl, G-418 selection) and then various single clones were infected with EGFP. Those clones, which expressed functional pwzl (identified by green fluorescence when inspected under UV light in conjunction with a fluorescein isothiocyanate (FITC) filter), were pooled and used for control reasons. The parental clones, which were identified by this assay (N.1pwzl) to express the functional retrovirus receptor, were also pooled and this pooled clone was subsequently infected with ectopic mouse retrovirus containing Cdc25A. This procedure generated five independent Cdc25A pools from two independently packaged retrovirus stocks. Cdc25A overexpression was tested by Northern and Western blot analyses.

\section{Production of retrovirus titre}

Phoenix cells were grown in $100 \mathrm{~mm}$ dishes in DMEM, supplemented with $10 \%$ FCS and $50 \mu \mathrm{g} / \mathrm{ml}$ hygromycin B. The transfection procedure (Transfectam) was upscaled for $100 \mathrm{~mm}$ dishes and performed, as described in the Promega protocol. The cells were transfected at $80 \%$ confluence with $12.5 \mu \mathrm{g}$ plasmid DNA (concentration $1 \mu \mathrm{g} / \mu \mathrm{l}$ ) in $37.5 \mu \mathrm{l}$ Transfectam (1:3 ratio w/vol). After $1 \mathrm{~h}$ of incubation, the medium was replaced by $10 \mathrm{ml}$ fresh medium with $10 \%$ FCS. After $24 \mathrm{~h}$, the medium was replaced with $4 \mathrm{ml}$ of complete medium (10\% FCS). At $48 \mathrm{~h}$ after transfection, the retrovirus containing cell culture supernatant was filtered $(0.22 \mu \mathrm{m}$ filter), aliquoted, shock-frozen in liquid nitrogen and stored at $-80^{\circ} \mathrm{C}$.

\section{Infection of cells}

N.1-pwzl cells were grown in six-well plates to $50 \%$ confluence. A measure of $500 \mu \mathrm{l}$ virus suspension was mixed with $500 \mu \mathrm{l}$ MEM, containing $10 \%$ FCS. Then Polybrene (Sigma) was added to a final concentration of
$4 \mu \mathrm{g} / \mathrm{ml}$. After an infection period of $3 \mathrm{~h}$ in the cell culture incubator, $2 \mathrm{ml}$ of MEM with $10 \%$ FCS was added. After $24 \mathrm{~h}$, cells were transferred into larger dishes to allow cell growth. At $48 \mathrm{~h}$ after infection, a selective medium ( $1 \mu \mathrm{g} / \mathrm{ml}$ puromycin, Sigma) was added to kill noninfected cells. After 10-12 days of selection, the puromycin concentration was reduced to $0.4 \mu \mathrm{g} / \mathrm{ml}$.

Several independent Cdc25A and control pools of infected N.1-pwzl cells were used for further experiments.

\section{Immunocytochemistry}

Cell clones were grown on siliconised glass slides. Then, cells were washed twice with phosphate-buffered saline (PBS) ( $\mathrm{pH} 7.2)$, air-dried, fixed with ice-cold acetic acid : ethanol $(1: 3)$ for $10 \mathrm{~min}$ and permeabilised with Triton X-100 (0.5\% in PBS) for $3 \mathrm{~min}$ at room temperature. Then slides were washed three times with washing buffer $(0.5 \mathrm{M}$ Tris- $\mathrm{HCl}, \mathrm{pH}$ 7.5) to remove Triton $\mathrm{X}-100$. Anti-Cdc25A rabbit polyclonal antibody was diluted in $0.5 \mathrm{M}$ Tris buffer, 1\% BSA pH 7.5 (anti-Cdc25A antibody dilution was $1: 50$ of a $100 \mu \mathrm{g} / \mathrm{ml}$ stock) and incubated in a humid chamber for $1 \mathrm{~h}$ at room temperature. After washing, the slides were incubated with FITCconjugated second antibody (goat anti-rabbit IgG, dilution 1:30; Dako) for $30 \mathrm{~min}$. Finally, slides were covered with a mounting medium (Geltol mounting medium for fluorescence, Lipshaw) and a coverslip. For control, slides were exposed to the second antibody only.

\section{Nucleus-cytoplasm fractionation}

Cells were washed in PBS and lysed in buffer A (10 mM, (HEPES), $10 \mathrm{mM}$ $\mathrm{KCl}, 0.1 \mathrm{mM}$ ethylenediaminetetraacetic acid (EDTA), $0.1 \mathrm{mM}$ EGTA, $1 \mathrm{mM}$ DL-dithiothreitol (DTT), 1.5\% NP-40, PIM, phenylmethylsulphonyl fluoride (PMSF)), on ice for $10 \mathrm{~min}$ and centrifuged at $12000 \mathrm{rpm}$. Supernatants were collected as cytoplasmic extracts.

The pellets were washed, resuspended in buffer $B(20 \mathrm{mM}$ HEPES, $400 \mathrm{mM} \mathrm{NaCl}, 1 \mathrm{mM}$ EDTA, $1 \mathrm{mM}$ EGTA, $1 \mathrm{mM}$ DTT, 0.05\% NP-40, PIM, PMSF) and agitated at $4{ }^{\circ} \mathrm{C}$ for $20 \mathrm{~min}$. After centrifugation at $12000 \mathrm{rpm}$, the supernatants were collected as nuclear extracts. The extracts were analysed by Western blotting.

\section{Western blotting}

Experiments were terminated by washing attached cells twice with ice-cold PBS (pH 7.2) and harvesting the monolayer with $200 \mu$ l sodium dodecyl sulphate (SDS) sample buffer, or with the buffers indicated. The viscous samples were sonicated and equal amounts of total protein were separated by polyacrylamide gel electrophoresis (PAGE). Subsequent to the electrophoretic separation, the proteins were electroblotted onto PVDF-membranes (Hybond, Amersham) overnight at $4^{\circ} \mathrm{C}$. To confirm equal sample loading, membranes were stained with Poinceau $S$. After washing with PBS or TBS, membranes were blocked for $1 \mathrm{~h}$ (blocking solution: $5 \%$ nonfat dry milk in PBS containing $0.5 \%$ Tween-20 or in TBS containing $0.1 \%$ Tween-20) and washed $3 \times$ with PBS/Tween-20 (PBST) or TBS/Tween-20 (TBST). Then, membranes were incubated with the first antibody (in blocking solution) by gently rocking at $4^{\circ} \mathrm{C}$, overnight. Thereafter, the membranes were washed in blocking solution $(1 \times)$ and in PBS/TBST $(2 \times)$ and further incubated with the second antibody (peroxidase-conjugated goat anti-rabbit IgG or anti-mouse IgG, dilution $1: 2000-1: 5000$ in PBST or TBST; Calbiochem) for $1-2 \mathrm{~h}$. Chemoluminescence was developed by the ECL detection kit (Amersham, UK) and then membranes were exposed to Kodak X-OMAT UV films. 


\section{Cell death experiments and analysis}

Apoptotic cell death was induced by stimulation with TNFa. To determine the number of surviving cells, the individual N.1 clones were grown in sixwell plates until $20 \%$ confluence. After $24 \mathrm{~h}$ of serum withdrawal ( $0 \% \mathrm{FCS}$ ), TNFa was added for the times indicated. The surviving cells were trypsinised and pooled with supernatant cells and stained with Hoechst 33258/propidium iodide ( $\mathrm{HO} / \mathrm{Pl}$; Hoechst: final concentration $5 \mu \mathrm{g} / \mathrm{ml}$ and PI: final concentration $2 \mu \mathrm{g} / \mathrm{ml})$ to monitor nuclear chromatin condensation, using a 4'-6-diamino-2-phenylindol (DAPI) filter in connection with a Zeiss Axiovert microscope. ${ }^{42-44}$

Apoptosis of rat 423 cells, which was induced by serum withdrawal $( \pm 500 \mathrm{nM} 4-\mathrm{OHT})$, was measured as described. ${ }^{18}$

\section{Expression, in vitro phosphorylation of GST-FKHRL1 and conjugation to glutathione-sepharose}

The GST (in vector pGEX) and GST-FKHRL1 (aa 1-525) fusion protein were produced in $E$. coli strain BL21. Protein expression from pGEX plasmids was induced in liquid cultures by the addition of $1 \mathrm{mM}$ isopropyl [beta]-D-thiogalactoside (IPTG) for $1 \mathrm{~h}$. Cells were sonicated in PBS containing $0.1 \%$ Triton X-100 to obtain protein lysates. For purification and conjugation and immobilisation, the lysates containing GST (control) and GST-FKHRL1 were incubated with glutathione-sepharose for $1 \mathrm{~h}$ at $40^{\circ} \mathrm{C}$ with gentle agitation. After several washing steps, the immobilised GST and GST-FKHRL1 (conjugated to glutathione-sepharose) was incubated with native N.1 cell lysate and $1 \mathrm{mM}$ ATP to allow/enhance the phosporylation of GST-FKHRL1. Protein expression and phosphorylation status was analysed by Coomassie blue staining and Western blotting.

\section{Acknowledgements}

We thank the donators providing plasmids and cell lines (listed under 'Materials and Methods') and Anton Jaeger for helping with the figures. This work was supported in part by Jubilaeumsfonds der Oesterreichischen Nationalbank, Grant No. 9298, the Herzfelder'sche Familienstiftung and by the Unruhe Privatstiftung (to GK), by the Theodor Koerner Stiftungspreis (to GF) and by a research fellowship of the Medical Faculty of the University of Vienna (to MG).

\section{References}

1. Hernandez S, Hernandez L, Bea S, Pinyol M, Nayach I, Bellosillo B, Nadal A Ferrer A, Fernandez PL, Montserrat E, Cardesa A and Campo E (2000) cdc25a and the splicing variant cdc25b2, but not cdc25B1, -B3 or -C, are overexpressed in aggressive human non-Hodgkin's lymphomas. Int. J. Cancer 89: 148-152

2. Gasparotto D, Maestro R, Piccinin S, Vukosavljevic T, Barzan L, Sulfaro S and Boiocchi M (1997) Overexpression of CDC25A and CDC25B in head and neck cancers. Cancer Res. 57: 2366-2368

3. Cangi MG, Cukor B, Soung P, Signoretti S, Moreira Jr G, Ranashinge M, Cady B, Pagano M and Loda M (2000) Role of the Cdc25A phosphatase in human breast cancer. J. Clin. Invest. 106: 753-761

4. Galaktionov K, Lee AK, Eckstein J, Draetta G, Meckler J, Loda M and Beach D (1995) CDC25 phosphatases as potential human oncogenes. Science 269: 1575-1577

5. Nilsson I and Hoffmann I (2000) Cell cycle regulation by the Cdc25 phosphatase family. Prog. Cell Cycle Res. 4: 107-114

6. Draetta $G$ and Eckstein J (1997) Cdc25 protein phosphatases in cell proliferation. Biochim. Biophys. Acta 1332: M53-M63
7. Takizawa CG and Morgan DO (2000) Control of mitosis by changes in the subcellular location of cyclin-B1-Cdk1 and Cdc25C. Curr. Opin. Cell Biol. 12: 658-665

8. Hoffmann I, Draetta G and Karsenti E (1994) Activation of the phosphatase activity of human cdc25A by a cdk2-cyclin $\mathrm{E}$ dependent phosphorylation at the G1/S transition. EMBO J. 13: 4302-4310

9. Sandhu C, Donovan J, Bhattacharya N, Stampfer M, Worland $P$ and Slingerland J (2000) Reduction of Cdc25A contributes to cyclin E1-Cdk2 inhibition at senescence in human mammary epithelial cells. Oncogene 19: 5314-5323

10. Blomberg I and Hoffmann I (1999) Ectopic expression of Cdc25A accelerates the $\mathrm{G}(1) / \mathrm{S}$ transition and leads to premature activation of cyclin $\mathrm{E}$ - and cyclin $\mathrm{A}$ dependent kinases. Mol. Cell. Biol. 19: 6183-6194

11. Jinno S, Suto K, Nagata A, Igarashi $M$, Kanaoka $Y$, Nojima $H$ and Okayama $H$ (1994) Cdc25A is a novel phosphatase functioning early in the cell cycle. EMBO J. 13: 1549-1556

12. Sexl V, Diehl JA, Sherr CJ, Ashmun R, Beach D and Roussel MF (1999) A rate limiting function of cdc25A for $S$ phase entry inversely correlates with tyrosine dephosphorylation of Cdk2. Oncogene 18: 573-582

13. Gu Y, Rosenblatt J and Morgan DO (1992) Cell cycle regulation of CDK2 activity by phosphorylation of Thr160 and Tyr15. EMBO J. 11: 3995-4005

14. Saha P, Eichbaum Q, Silberman ED, Mayer BJ and Dutta A (1997) p21CIP1 and Cdc25A: competition between an inhibitor and an activator of cyclindependent kinases. Mol. Cell. Biol. 17: 4338-4345

15. Mailand N, Falck J, Lukas C, Syljuasen RG, Welcker M, Bartek J and Lukas J (2000) Rapid destruction of human Cdc25A in response to DNA damage. Science 288: 1425-1429

16. Conklin DS, Galaktionov K and Beach D (1995) 14-3-3 proteins associate with cdc25 phosphatases. Proc. Natl. Acad. Sci. USA 92: 7892-7896

17. Galaktionov K, Jessus $C$ and Beach D (1995) Raf1 interaction with Cdc25 phosphatase ties mitogenic signal transduction to cell cycle activation. Genes Dev. 9: 1046-1058

18. Fuhrmann G, Leisser C, Rosenberger G, Grusch M, Huettenbrenner S, Halama T, Mosberger I, Sasgary S, Cerni C and Krupitza G (2001) Cdc25A phosphatase suppresses apoptosis induced by serum deprivation. Oncogene 20: $4542-4553$

19. Zou X, Tsutsui T, Ray D, Blomquist JF, Ichijo H, Ucker DS and Kiyokawa $H$ (2001) The cell cycle-regulatory CDC25A phosphatase inhibits apoptosis signal-regulating kinase 1. Mol. Cell. Biol. 21: 4818-4828

20. Rosenberger G (1999) The function of cdc25A in active cell death. Master Thesis, Institute of Clinical Pathology, University of Vienna, Vienna, pp. 1-94

21. Jackson JG, Kreisberg JI, Koterba AP, Yee D and Brattain MG (2000) Phosphorylation and nuclear exclusion of the forkhead transcription factor FKHR after epidermal growth factor treatment in human breast cancer cells. Oncogene 19: 4574-4581

22. Brunet A, Park J, Tran H, Hu LS, Hemmings BA and Greenberg ME (2001) Protein kinase SGK mediates survival signals by phosphorylating the forkhead transcription factor FKHRL1 (FOXO3a). Mol. Cell. Biol. 21: 952-965

23. Brunet A, Bonni A, Zigmond MJ, Lin MZ, Juo P, Hu LS, Anderson MJ, Arden KC, Blenis J and Greenberg ME (1999) Akt promotes cell survival by phosphorylating and inhibiting a Forkhead transcription factor. Cell 96: 857868

24. Rena G, Prescott AR, Guo S, Cohen P and Unterman TG (2001) Roles of the forkhead in rhabdomyosarcoma (FKHR) phosphorylation sites in regulating 14-3-3 binding, transactivation and nuclear targeting. Biochem. J. 354: $605-612$

25. Dijkers PF, Medema RH, Pals C, Banerii L, Thomas NS, Lam EW, Burgering BM, Raaijmakers JA, Lammers JW, Koenderman L and Coffer PJ (2000) Forkhead transcription factor FKHR-L1 modulates cytokine-dependent transcriptional regulation of p27(KIP1). Mol. Cell. Biol. 20: 9138-9148

26. Dijkers PF, Medema RH, Lammers JW, Koenderman L and Coffer PJ (2000) Expression of the pro-apoptotic Bcl-2 family member Bim is regulated by the forkhead transcription factor FKHR-L1. Curr. Biol. 10: 1201-1204

27. Stahl M, Dijkers PF, Kops GJ, Lens SM, Coffer PJ, Burgering BM and Medema $\mathrm{RH}$ (2002) The forkhead transcription factor FoxO regulates transcription of p27Kip1 and Bim in response to IL-2. J. Immunol. 168: 5024-5031

28. Kops GJ and Burgering BM (1999) Forkhead transcription factors: new insights into protein kinase B (c-akt) signaling. J. Mol. Med. 77: 656-665 
29. Dijkers PF, Birkenkamp KU, Lam EW, Thomas NS, Lammers JW, Koenderman L and Coffer PJ (2002) FKHR-L1 can act as a critical effector of cell death induced by cytokine withdrawal: protein kinase B-enhanced cell survival through maintenance of mitochondrial integrity. J. Cell Biol. 156: 531-542

30. Grusch M, Rosenberger G, Fuhrmann G, Braun K, Titscher B, Szekeres T, Fritzer-Skekeres M, Oberhuber G, Krohn K, Hengstschlaeger M, Krupitza G and Jayaram HN (1999) Benzamide riboside induces apoptosis independent of Cdc25A expression in human ovarian carcinoma N.1 cells. Cell Death Differ. 6 : 736-744

31. Krupitza G, Grusch M, Braun K, Fuhrmann G, Steinbrugger R, Hulla W, Simonitsch I, Chott A and Hengstschlager M (1998) TNFalpha-mediated cell death is independent of cdc25A. Cell Death Differ. 5: 758-764

32. Fuhrmann G, Rosenberger G, Grusch M, Klein N, Hofmann J and Krupitza $G$ (1999) The MYC dualism in growth and death. Mutat. Res. 437: 205-217

33. Galaktionov K, Chen X and Beach D (1996) Cdc25 cell-cycle phosphatase as a target of c-myc. Nature 382: 511-517

34. Macdonald K and Bennett MR (1999) cdc25A is necessary but not sufficient for optimal c-myc-induced apoptosis and cell proliferation of vascular smooth muscle cells. Circ. Res. 84: 820-830

35. Wijayaratne AL and McDonnell DP (2001) The human estrogen receptor-alpha is a ubiquitinated protein whose stability is affected differentially by agonists, antagonists, and selective estrogen receptor modulators. J. Biol. Chem. 276: 35684-35692

36. Brunet A, Kanai F, Stehn J, Xu J, Sarbassova D, Frangioni JV, Dalal SN DeCaprio JA, Greenberg ME and Yaffe MB (2002) 14-3-3 transits to the nucleus and participates in dynamic nucleocytoplasmic transport. J. Cell Biol. 156: $817-828$
37. Nakae J, Barr V and Accili D (2000) Differential regulation of gene expression by insulin and IGF-1 receptors correlates with phosphorylation of a single amino acid residue in the forkhead transcription factor FKHR. EMBO J. 19: 989-996

38. Tang ED, Nunez G, Barr FG and Guan KL (1999) Negative regulation of the forkhead transcription factor FKHR by Akt. J. Biol. Chem. 274: 16741-16746

39. Shin I, Bakin AV, Rodeck U, Brunet A and Arteaga CL (2001) Transforming growth factor beta enhances epithelial cell survival via Akt-dependent regulation of FKHRL1. Mol. Biol. Cell 12: 3328-3339

40. Nakamura N, Ramaswamy S, Vazquez F, Signoretti S, Loda M and Sellers WR (2000) Forkhead transcription factors are critical effectors of cell death and cell cycle arrest downstream of PTEN. Mol. Cell. Biol. 20: 8969-8982

41. Littlewood TD, Hancock DC, Danielian PS, Parker MG and Evan GI (1995) A modified oestrogen receptor ligand-binding domain as an improved switch for the regulation of heterologous proteins. Nucleic Acids Res. 23: 1686-1690

42. Grusch M, Polgar D, Gfatter S, Leuhuber K, Huettenbrenner S, Leisser C, Fuhrmann G, Kassie F, Steinkellner H, Smid K, Peters GJ, Jayaram HN, Klepal W, Szekeres T, Knasmuller S and Krupitza G (2002) Maintenance of ATP favours apoptosis over necrosis triggered by benzamide riboside. Cell Death Differ. 9: 169-178

43. Grusch M, Fritzer-Szekeres M, Fuhrmann G, Rosenberger G, Luxbacher C, Elford HL, Smid K, Peters GJ, Szekeres T and Krupitza G (2001) Activation of caspases and induction of apoptosis by novel ribonucleotide reductase inhibitors amidox and didox. Exp. Hematol. 29: 623-632

44. Rosenberger G, Fuhrmann G, Grusch M, Fassl S, Elford HL, Smid K, Peters GJ, Szekeres T and Krupitza G (2000) The ribonucleotide reductase inhibitor trimidox induces c-myc and apoptosis of human ovarian carcinoma cells. Life Sci. 67: 3131-3142 